\title{
Gênero e Sexualidade: Análise das Publicações na Revista Psicologia: Ciência e Profissão (1995-2019)
}

\author{
Adolfo Pizzinato ${ }^{1}$ \\ Damião Soares de Almeida-Segundo ${ }^{1}$ \\ ${ }^{1}$ Universidade Federal do Rio Grande do Sul, RS, Brasil. $\quad{ }^{1}$ Universidade Federal do Rio Grande do Sul, RS, Brasil. \\ Anna Paula Uziel ${ }^{2}$ \\ ${ }^{2}$ Universidade do Estado do Rio de Janeiro, RJ, Brasil.
}

\begin{abstract}
Resumo: O presente estudo buscou analisar as publicações na temática de gênero e sexualidade da revista Psicologia: Ciência e Profissão. Foi realizada busca por meio da ferramenta de pesquisa da própria revista utilizando os termos "gênero" ou "sexualidade". O banco final incluído na análise foi constituído por 70 artigos publicados entre 1995 e 2019. Foram feitas classificação hierárquica descendente e análise de similitude com o corpus formado pelos resumos dos artigos por meio do software Iramuteq. Analisaram-se 340 segmentos de texto, em que se reteve $81,76 \%$ do total 278 UCEs), gerando cinco classes: Sexualidade e desenvolvimento, Estudos de intervenção, Perspectivas críticas da diversidade, Violência contra as mulheres e Pesquisas empíricas. Percebeuse a formação de dois eixos temáticos das pesquisas em diferentes momentos, um voltado às discussões sobre gênero e diversidade sexual e outro relacionado com uma perspectiva de disparidades de gênero e sexismo. Ambos foram influenciados pelas determinações legais no período, como leis e decisões judiciais. Tais posicionamentos jurídico-legais foram importantes para consolidar avanços nas políticas de igualdade e implicaram o campo de saberes e fazeres da Psicologia, que, por sua vez, tensiona esses debates na sociedade brasileira.
\end{abstract}

Palavras-chave: Gênero, Sexualidade, Produção Acadêmica.

\section{Gender and Sexuality: Analysis of Publications in the Journal Psicologia: Ciência e Profissão (1995-2019)}

\begin{abstract}
The present study aims to analyze the publications on gender and sexuality in the journal Psicologia: Ciência e Profissão. An investigation was carried out using the search tool of the magazine itself using the terms "gender" or "sexuality". The final bank included in the analysis consisted of 70 articles published between 1995 and 2019. Descending Hierarchical Classification and Similitude Analysis were made with the corpus formed by the abstracts of the articles using the Iramuteq software. 340 text segments (ST) were analyzed, in which $81.76 \%$ of the total (278 UCEs) was retained, generating 5 classes - Sexuality and Development; Intervention Studies; Critical Perspectives of Diversity; Violence Against Women and Empirical Research. It was noticed the formation of two axes of research themes at different moments, one focused on discussions about gender and sexual diversity and the other related to a perspective of gender and sexism disparities. Both were influenced by legal provisions in the period, such as laws and court decisions. Such legal positions were important to consolidate advances in equality policies and involved the field of knowledge and practices in Psychology that, in turn, tension these debates in Brazilian society.
\end{abstract}

Keywords: Gender, Sexuality, Academical Production. 


\title{
Género y Sexualidad: Análisis de Publicaciones en la Revista Psicologia: Ciência e Profissão (1995-2019)
}

\begin{abstract}
Resumen: Este estudio buscó analizar las publicaciones sobre género y sexualidad en la revista Psicologia: Ciência e Profissão. Se realizó una búsqueda utilizando la herramienta de búsqueda de la propia revista utilizando los términos "género" o "sexualidad". El banco final incluido en el análisis consistió en 70 artículos publicados entre 1995 y 2019. La clasificación jerárquica descendente y el análisis de similitud se realizaron con el corpus formado por los resúmenes de los artículos utilizando el software Iramuteq. Se analizaron 340 segmentos de texto (ST), en los que se retuvo el $81.76 \%$ del total (278 UCE), generando 5 clases: Sexualidad y Desarrollo; Estudios de intervención; Perspectivas críticas de la diversidad; Violencia contra la mujer e investigación empírica. Se observó la formación de dos ejes de temas de investigación en diferentes momentos, uno centrado en discusiones sobre género y diversidad sexual y el otro relacionado con una perspectiva de disparidades de género y sexismo. Ambos fueron influenciados por disposiciones legales en el período, como las leyes y las decisiones judiciales. Tales posiciones legales fueron importantes para consolidar los avances en las políticas de igualdad e involucraron el campo del conocimiento y las prácticas en Psicología que, a su vez, tensionan estos debates en la sociedad brasileña.
\end{abstract}

Palabra clave: Género, Sexualidad, Producción Académica.

\section{Introdução}

Em 2016, o Geledés - Instituto da Mulher Negra elencou, em seu site, 16 obras que consideram essenciais para quem estuda gênero e sexualidade, como os clássicos História da sexualidade I, de Michel Foucault, Pensando o sexo: notas para uma teoria radical das políticas da sexualidade, de Gayle Rubin, Problemas de gênero, de Judith Butler, Gênero: uma categoria útil para análise histórica, de Joan Scott, Manifesto contra-sexual, de Paul Beatriz Preciado, além de brasileiras, consagradas, como os variados livros de Guacira Lopes Louro, textos de Sérgio Carrara, Julio Simões, Berenice Bento, entre outras.

Além das publicações selecionadas pelo Geledés, também poderia destacar-se, ainda nos anos 1990, o texto de Sonia Corrêa e Rosalyn Petchesky (1996), que parte de uma perspectiva feminista para aportar para o campo dos direitos sociais, dos direitos sexuais e reprodutivos. Caminho semelhante faz o trabalho de Roger Raupp Rios (2006), dez anos depois.

No atual milênio, não parece demais afirmar que o campo de estudos de gênero e sexualidade está consolidado no Brasil, seja nas Ciências Sociais, nas
Ciências Sociais Aplicadas ou nas Ciências Humanas, e expandindo-se para campos tidos como das ciências da saúde e exatas. Gênero é uma poderosa lente para aproximar as relações de poder naturalizadas no cotidiano. Uma encrenca, provoca Sandra Azerêdo (2010), porque o gênero não se deixa disciplinar, prática comum no exercício acadêmico em geral e, também, nas teorias e práticas da Psicologia.

Os anos 1990 foram, no mundo todo, um momento de conquistas de direitos. A descoberta do HIV e da aids completava uma década e desvelava, para muitos familiares, a homossexualidade de seus filhos. Nos mais diversos países, as lutas por direitos decorrentes da conjugalidade entre pessoas do mesmo sexo vão se transformando em leis que reconhecem a união e seus efeitos patrimoniais. São incipientes ainda, naquele momento, as discussões sobre família, que começam uma década depois. No Brasil, o projeto de lei da então deputada Marta Suplicy, de 1995, sobre parceria civil entre pessoas do mesmo sexo, nunca pôde ser votado, e decisões referentes tanto à conjugalidade quanto à adoção por casais gays ou lésbicos, ou ainda de casamento e família, acontecem todas no campo judicial, sejam pontuais, na comarca em que os casos são julgados, seja com a decisão do Supremo 
Tribunal Federal (STF) em 2011, que tem força de lei. Esta decisão reconheceu como união estável aquela entre dois homens ou duas mulheres, o equivalente à de casais heterossexuais, e dois anos depois, em 2013, a Resolução 175 do Conselho Nacional de Justiça (CNJ) proibiu que cartórios recusassem a celebração de casamentos civis entre pessoas do mesmo sexo, obrigando-os a converter a união estável em casamento sempre que fosse do desejo do casal. Ou seja: conquista um direito pela negação de sua proibição, e não como uma conquista cidadã por via parlamentar.

Ainda nos anos 1990 crescem os estudos sobre homossexualidade no Brasil. Richard Parker (1995; Parker, Quemmel, Guimares, Mota \& Terto Junior, 1995) promoveu variadas pesquisas na época, fazendo uma articulação entre sociedade civil, movimento social e academia. O mestrado e o doutorado de Veriano Terto Junior $(1989 ; 1997)$ exemplificam bem a expansão de pesquisas neste tema: No escurinho do cinema: socialidade orgiástica nas tardes cariocas e Reinventando a vida: histórias sobre homossexualidade e aids no Brasil.

No que tange aos direitos das mulheres, nos anos 1980 nasce a PNAISM (Política de Atenção Integral à Saúde da Mulher), no bojo do movimento de abertura do país, com o fim da ditadura militar. Ainda naquela década são implantadas as primeiras DEAM (Delegacia Especializada no Atendimento à Mulher) em São Paulo e no Rio de Janeiro, vitória da luta árdua do movimento feminista brasileiro, que se mantém firme na sociedade civil e contribui para as primeiras políticas públicas claramente desenhadas para mulheres.

Alguns anos mais tarde, o governo Lula (20032011) dá destaque a políticas para mulheres, criando uma Secretaria com status de ministério, a Secretaria Especial de Políticas para as Mulheres (SPM). Muito em função da parceria, não sem tensões, entre o movimento feminista e a academia, foi criado o prêmio Construindo a Igualdade de Gênero, no âmbito do Programa Mulher e Ciência, para redações de ensino médio e artigos científicos oriundos da graduação, de dissertações ou teses, uma parceria entre duas secretarias do Ministério da Educação - Secadi (Secretaria de Educação Continuada, Alfabetização, Diversidade e Inclusão) e SEB (Sistema Educacional Brasileiro) -, a SPM e o CNPq (Conselho Nacional de Desenvolvimento Científico e Tecnológico), além de editais de pesquisa com temáticas de gênero.
Isso fortaleceu ainda mais o campo que já vinha sendo sedimentado com os concursos da Fundação MacArthur nos anos 1980, e o apoio da Fundação Ford. Naquele início dos anos 2000, com o incentivo da SPM, não apenas o ensino superior era contemplado, mas projetos e ações de escolas ou secretarias municipais ou estaduais que promovessem a igualdade de gênero também eram premiados.

Ainda no governo Lula, foram muitas as ações promovidas no sentido de garantia de direitos, como, por exemplo, a criação do 180, uma linha direta para denúncia de violência contra a mulher, com ligação gratuita de qualquer lugar do país. No campo legal, em 2006 é promulgada a lei Maria da Penha (Lei no 11.340), no bojo do entendimento constitucional, artigo $8^{\circ}$, de que a violência contra a mulher não é uma questão privada, baseada na Convenção sobre a Eliminação de Todas as Formas de Discriminação contra as Mulheres e na Convenção Interamericana para Prevenir, Punir e Erradicar a Violência contra a Mulher. Esta lei, que cria mecanismos para coibir e prevenir a violência contra a mulher, trouxe mudanças significativas nos procedimentos processuais relacionados à violência, tendo sofrido modificações em 2019 no sentido de agilizar os procedimentos.

No entanto, se muitas foram as conquistas no campo dos direitos sexuais e reprodutivos no país, são crescentes os retrocessos. Em 2011, no governo Dilma Rousseff, o MEC, sob comando de Fernando Haddad, lançou um material didático que incluía vídeos e livros para que docentes de ensino médio trabalhassem com seus/suas alunos/as questões sobre gênero e sexualidade. Tornando as fake news já bastante poderosas naquele momento, a desinformação, a mentira e a má-fé transformaram o material pouco conhecido sobre o combate ao preconceito e à homofobia no que se passou a denominar "kit gay", seguido da explicação falsa de que se tratava de um conteúdo doutrinário para crianças cujo objetivo era transformá-las em homossexuais, afirmando a inexistência de diferenças entre os gêneros, tão naturalizadas em nossa sociedade. Ainda que a formulação não fizesse sentido numa lógica formal (piagetiana), foi difundida de tal forma entre a população, que levou o governo federal da época a suspender a distribuição do material num jogo de negociação política vã para a manutenção da própria existência do governo Dilma, per se alvo de profunda misoginia da imprensa e de setores políticos mais conservadores. Não à toa, hoje tais grupos comandam o regime político. 
Em 2014, o Plano Nacional de Educação, que pauta as diretrizes da área por uma década, teve excluída qualquer referência a gênero. A pressão de grupos religiosos e o avanço da extrema direita e demais movimentos conservadores no Brasil foram cruciais para esta exclusão. Gênero, temática fundamental na diminuição da desigualdade em nosso país, foi descartado de todos os planos de educação, nos três níveis - federal, estaduais e municipais -, e dentre os principais articuladores políticos dessa exclusão está uma peculiar conjunção de grupos religiosos reacionários, grupos conservadores de toda monta, defensores do liberalismo econômico e da violência. A bandeira antigênero levantada por esses grupos parece ter sido crucial para o golpe parlamentar que depôs a presidenta eleita sob alegações de frágil manutenção legal.

Aparentemente o embate antigênero teve papel chave na construção não apenas de um discurso midiático sobre o risco social que o governo da época representava, mas também na aglutinação de setores outrora miúdos da oposição, o chamado "baixo clero" - porseu caráter fisiológico -, com setores da direita estabelecida politicamente. Como destaca Junqueira (2018), nas ofensivas antigênero no mundo todo

. . . engajam-se setores e grupos interessados em promover uma agenda política moralmente regressiva, especialmente (mas não apenas) orientada a conter ou anular avanços e transformações em relação a gênero, sexo e sexualidade, além de reafirmar disposições tradicionalistas, pontos doutrinais dogmáticos e princípios religiosos "não negociáveis". Na esteira dessas investidas, constroem-se discursos inflamados com vistas a produzir ou a alimentar pânico moral, por meio de estratégias político-discursivas voltadas a arregimentar a sociedade em uma batalha em defesa da "família tradicional" (p. 451).

No início de 2019, houve quem entendesse como piada a frase da pastora neopentecostal e atual ministra da Mulher, da Família e dos Direitos Humanos, do governo recém-empossado, a respeito das cores azul para menino e rosa para menina. Seria, se não fosse apenas o início de um retrocesso declarado, posicionamento oficial do Estado brasileiro, com repercussão nos discursos na ONU, onde o Brasil sempre foi vanguarda, nas questões de gênero e sexualidade, e de consequências ainda pouco analisadas, mas com pistas bastante significativas, como o aumento do feminicídio $^{1}$, neste pouco mais de um ano do governo.

Nesta mesma linha, em maio de 2019, o Ministério da Saúde decidiu fundir o Departamento de Infecções Sexualmente Transmissíveis com outros programas de doenças crônicas, um claro desmonte do programa de aids brasileiro, que sempre foi referência internacional. Como fica evidente em matéria no site da Abia (Associação Brasileira da Indústria de Alimentos) do dia 28 daquele mês, não se considerou que as doenças agora reunidas possuem diferentes formas de transmissão, escalas de impacto, segmentos populacionais diretamente afetados, dinâmicas sociais, indicadores e fatores epidemiológicos.

Ainda que tímidas, as respostas sociais frente ao conservadorismo crescente no Brasil e em muitos países do mundo vêm acontecendo. Nesse contexto, é importante destacar o papel do Conselho Federal de Psicologia (CFP), pela adoção de posturas democráticas nos debates públicos atuais sobre gênero e sexualidade. A autarquia foi criada em 1971 com a finalidade de orientar, disciplinar e fiscalizar o exercício da profissão de psicólogo e zelar pela fiel observância dos princípios da ética e da disciplina da classe (Decreto no ${ }^{0} 79.822 / 1977$ ). O órgão tem editado resoluções que antecipam avanços na área e estabelecem posicionamento pela defesa dos direitos de grupos minoritários. Assim, por exemplo, por meio de sua Resolução no 1 , em 1999, estabeleceu diretrizes para a atuação das(os) psicólogas (os) com relação à orientação sexual. Determinou que as(os) profissionais devem contribuir para o fim das estigmatizações e discriminações contra homossexuais e proibiu práticas que patologizam a homossexualidade. Contudo, é constante a tentativa de enfraquecer o órgão, e a atuação democrática do CFP tem sido ameaçada nos últimos anos pelo desejo de imposição de preceitos religiosos na atuação do órgão, com a ameaça a sua laicidade, vindo da própria categoria ou do Congresso Nacional.

\footnotetext{
1 Ver, por exemplo, https://g1.globo.com/sp/sao-paulo/noticia/2019/08/07/casos-de-feminicidio-aumentam-44percent-no-1osemestre-de-2019-em-sp.ghtml
} 
Assim, como nos lembram Rios, Resadori, Silva e Vidor (2017), sua atuação deve ser norteada pela proteção do interesse da coletividade em detrimento de interesses individuais, seja dos profissionais fiscalizados, seja de dirigentes do Conselho. Deve prezar pela defesa do interesse público a respeito da atuação daqueles que exercem a profissão de psicólogo, e não a soma de interesses dos profissionais representados no Conselho. A intenção de colocar interesses privados acima dos interesses coletivos no funcionamento de um órgão de classe, assim como a atuação profissional baseada em orientações religiosas, são uma ameaça à laicidade e à democracia, o que pode desviar o Conselho de suas finalidades institucionais. Como um agente estatal, o Sistema Conselhos está sujeito a todos os preceitos constitucionais dirigidos ao Estado.

Cada vez mais esta discussão é necessária. O avanço da extrema direita e a tentativa de se misturar Psicologia e doutrinas religiosas, bem como as investidas contra as Resoluções 001/99 e 01/2018, que interditam tratamento e cura das homossexualidades e transexualidades, respectivamente, motivadas pela afirmação, por diversas instâncias sociais e científicas, de que não são doenças, mas expressões de desejo e identidade humanos, exigem posicionamentos éticos claros do nosso campo de saber.

A regulação ética da profissão também passa pela continuidade da preparação profissional. Neste sentido, a vinculação da revista Psicologia: Ciência e Profissão ao Conselho Federal de Psicologia não apenas dá legitimidade à publicação, como faz que o Conselho cumpra sua importante função de acompanhamento do exercício profissional, por meio da difusão de material de pesquisa de qualificada, que permite uma formação continuada e atualização constante. A Psicologia é um saber em movimento, e a possibilidade contínua de difusão do conhecimento científico, neste sentido, é fundamental e, no caso do campo dos estudos de gênero e sexualidade, recobra importância - não apenas pelo protagonismo da área frente às políticas reacionárias do atual regime, mas também pela maturidade do debate na Psicologia brasileira, seja no campo mais teórico ou mais aplicado.

A Psicologia brasileira, tanto em nível político-institucional como em nível acadêmico, tem produzido debates, pesquisas e ações que também colocam nossa categoria profissional e área do conhecimento em posição de destaque na construção de saberes e fazeres cada vez mais democráticos, academicamente maduros e eticamente implicados na promoção da equidade de gênero e sexualidade.

Nas publicações científicas brasileiras, a discussão sobre gênero costuma aparecer de duas formas: em revistas especializadas no campo, como o são a $R E F$ Revista Estudos Feministas (UFSC), os Cadernos Pagu (Unicamp) e Sexualidad, Salud y Sociedad (Clam/IMS/ Uerj), ou artigos sobre gênero em revistas das diversas áreas. Lago e Uziel (2014) buscaram analisar a incidência de artigos de Psicologia sobre a temática na revista Estudos Feministas entre 2003 e 2014, indicando um crescimento da produção de autoras/es com formação e/ou atuação no campo da Psicologia. O que se propõe aqui é quase este estudo às avessas: partimos de uma importante e reconhecida revista no campo da Psicologia, a Psicologia: Ciência e Profissão, para analisar que temáticas de gênero e sexualidade aparecem, que tipos de estudo a revista acolheu e quem e de onde são os/as autores/as. Enfim, são aspectos que nos dão elementos para mapear o campo de estudos de gênero na Psicologia, considerando o desenvolvimento político dessas temáticas na sociedade brasileira dos meados dos anos 1990 até os dias atuais.

\section{Método}

\section{Procedimentos}

Para mapear o panorama das publicações do campo de gênero/sexualidade na história da revista, realizou-se um levantamento por meio da própria ferramenta de pesquisa da página web da revista Psicologia: Ciência e Profissão, na plataforma Scielo. As buscas foram realizadas utilizando os termos "gênero" e "sexualidade" com o operador booleano "OR”. Não houve delimitação de idioma ou de período de busca, abarcando todas as publicações disponíveis on-line até 2019. Foram incluídos apenas os artigos que tinham como tema principal ou transversal os estudos sobre gênero ou sexualidade, eliminado aqueles que se referiam a essas dimensões apenas para caracterização amostral, por exemplo. Para tanto, foram analisados o objetivo e os tópicos de método e discussão dos artigos. Com base nesse levantamento, foram incluídos todos os artigos publicados na revista segundo esses critérios e disponíveis on-line. Realizou-se a transcrição dos resumos dos artigos selecionados para formar um corpus textual único a ser analisado. 


\section{Análise de dados}

O conteúdo textual do corpus foi analisado por meio de classificação hierárquica descendente (CHD) e de análise de similitude com o Iramuteq (Camargo \& Justo, 2013). Esse software permite criar categorias ou classes considerando a frequência das palavras utilizadas, a afinidade semântica e o contexto em que elas se apresentam e o nível de relação entre elas, que é mensurado por teste qui-quadrado. Além disso, apresenta outputs gráficos que facilitam a visualização do conteúdo analisado. Assim, permite uma abordagem tanto quantitativa, pois analisa as palavras, formando clusters por frequência, relação e proximidade/distância, como qualitativa, já que cabe ao pesquisador dar significado às classes agrupadas.

\section{Resultados e discussão}

As buscas pelos termos geraram 84 resultados com pelo menos um dos termos. Dos 84 artigos, 14 foram excluídos por não tratarem direta ou indiretamente do tema gênero ou sexualidade. Assim, o banco final incluído na análise desse estudo foi constituído por 70 artigos. Os resultados descritivos das publicações por ano e macrorregião do autor principal do artigo estão na Figura 1 e Tabela 1, respectivamente. Iniciaremos apresentando os dados de distribuição por ano e região de procedência da publicação, para posteriormente expormos as categorias analíticas.

Segundo os critérios de busca aqui utilizados, o primeiro artigo publicado sobre gênero/sexualidade na revista foi em 1995, e as publicações só retomaram no ano de 2000. Talvez as publicações anteriores a 1995, bem como aquelas entre 1996 e 1999, apenas não estejam disponíveis on-line, e, por isso, não foram incluídas no mapeamento. Desde então, o número de publicações não seguiu um padrão linear ao longo dos anos (Figura 1). Em 2018, ocorreu o número máximo de trabalhos publicados sobre os temas em um único ano (9), e o período de 2001 a 2002 teve apenas três publicações. Destaque também para 2010 (7), 2014 (6), 2016 (8) e 2019 (8), anos em que o número de artigos foi maior que 5. Assim, se os marcos legais relacionados a sexualidade/gênero se iniciam a partir dos anos 2000, é na década seguinte que há uma repercussão com o aumento expressivo das publicações sobre o tema.

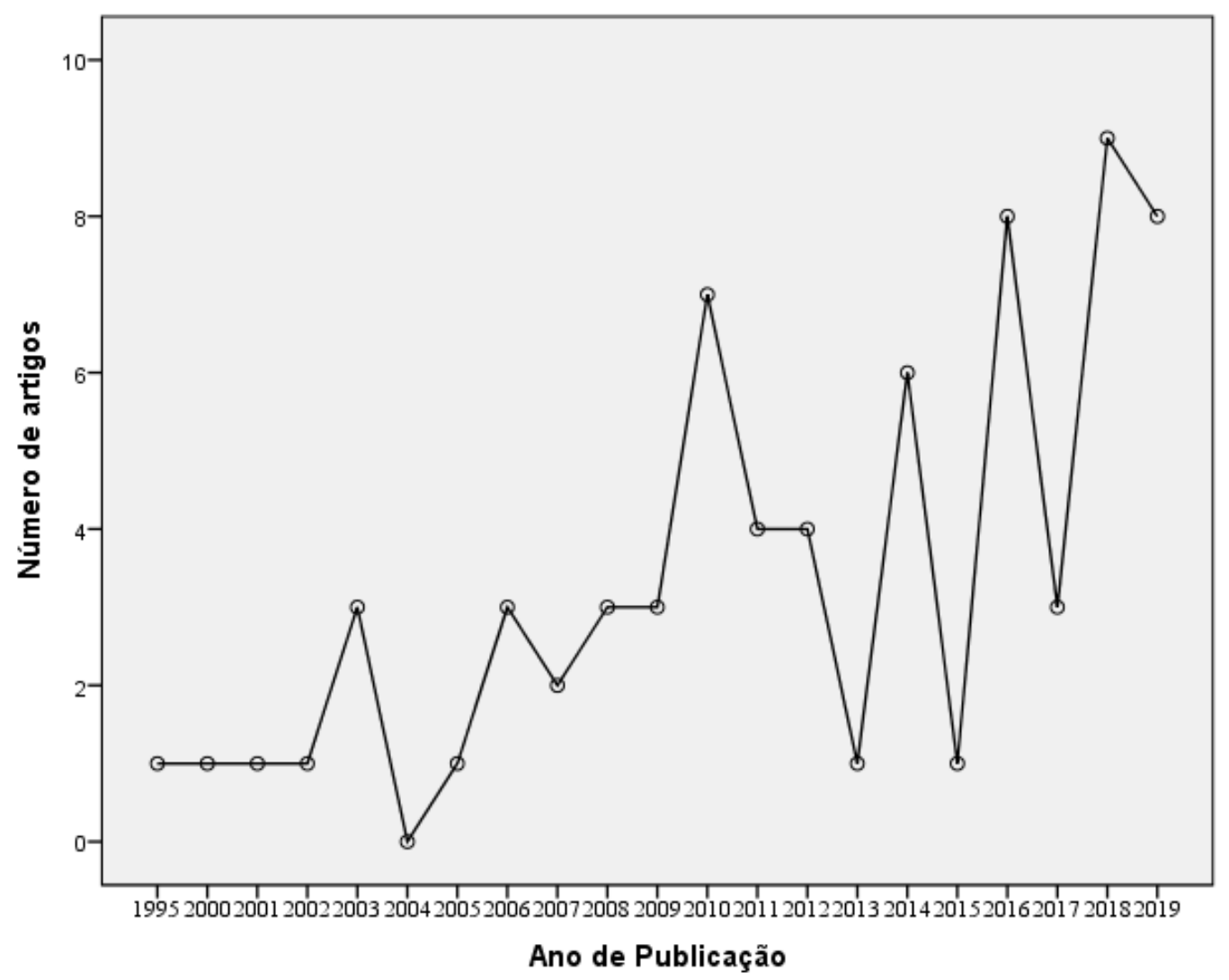

Figura 1.

Distribuição das publicações sobre gênero/sexualidade por ano. 
Já em relação à macrorregião geográfica, a região Sudeste (24) aparece como a que tem maior número de publicações, e a Norte (4) com a menor quantidade. A região Sul (17), apesar de ter apenas três estados, teve número expressivo de publicações. O eixo Sudeste-Sul concentra grande número das universidades do país e, consequentemente, dos grupos de pesquisa que têm se voltado para o estudo de sexualidade/gênero. Contudo, é importante o fato de que todas as regiões possuem contribuições.

A Figura 2 traz o dendograma com o resultado da classificação hierárquica descendente (CHD). A análise do corpus contou com 340 segmentos de texto (ST), retendo $81,76 \%$ do total (278 UCEs Unidades de Contexto Elementar), os quais se organizaram em cinco classes. Inicialmente, o corpus se dividiu em dois subcorpora. O primeiro, composto pela classe 5, englobou "Pesquisas Empíricas" (ou seja, pesquisas que implicam diretamente outras pessoas como informantes para a composição do corpus de informações a ser analisado), cujo tema principal não costuma ser sexualidade/gênero, mas onde tais conceitos operam como um prisma de análise ou comparação. Em seguida, vem o subcorpus "Estudos de Gênero e Diversidade Sexual”, formado pelas classes $1,2,3$ e 4, relacionado a estudos que abarcam temas diretamente ligados às discussões acerca de gênero e sexualidade. Esse subcorpus se dividiu novamente, opondo as classes 1 e 4 às classes 2 e 3 (Figura 2).

\section{Tabela 2.}

Publicação por região de origem do autor principal.

\begin{tabular}{lccccc}
\hline & $\begin{array}{c}\text { Centro- } \\
\text { Oeste }\end{array}$ & Nordeste & Norte & Sudeste & Sul \\
\hline $\mathrm{n}$ & 12 & 13 & 4 & 24 & 17 \\
\hline
\end{tabular}

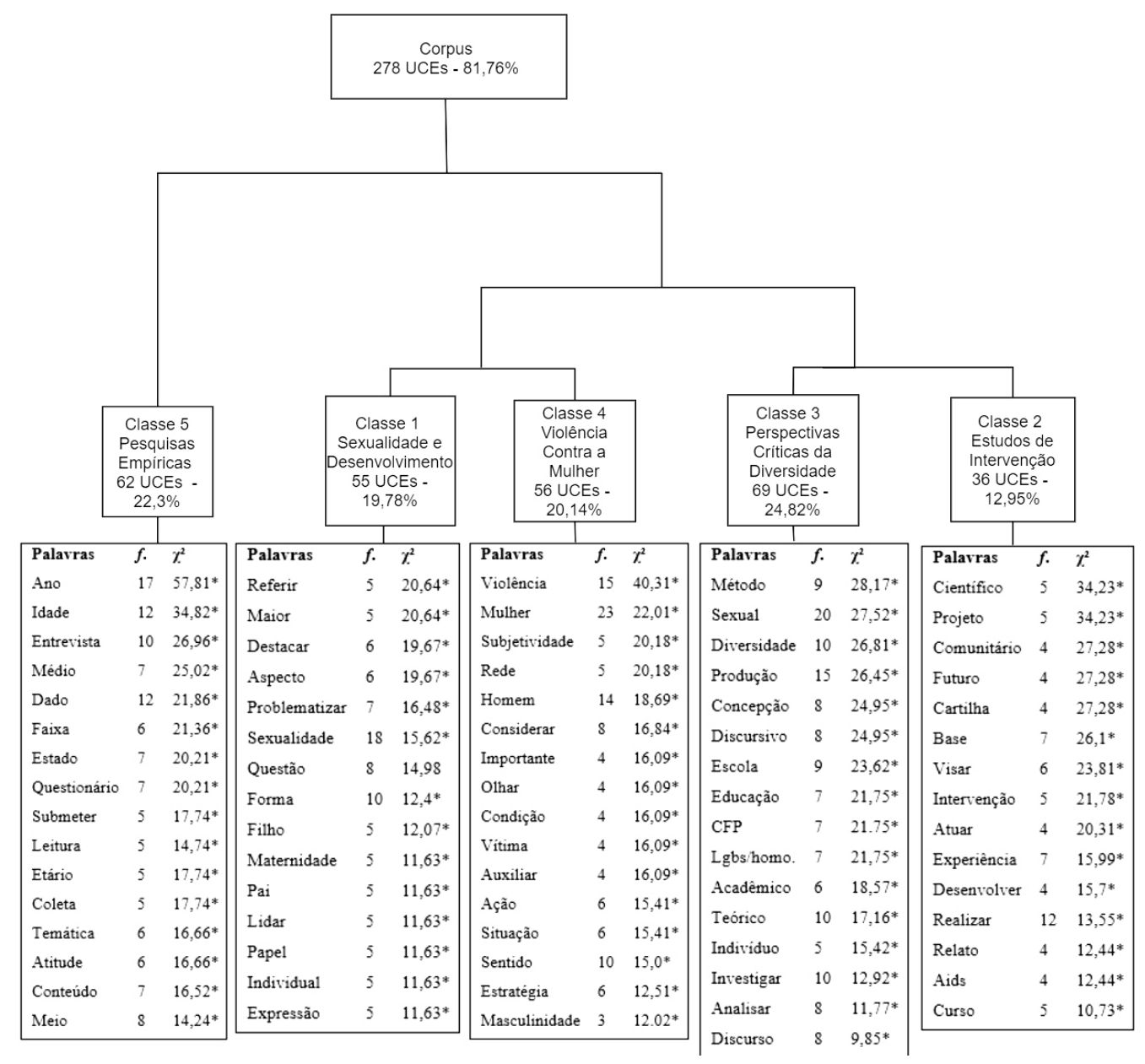

Figura 2.

Análise do corpus pelo método de classificação hierárquica descendente. Nota: ${ }^{*} \mathrm{p}<0,01$; teste qui-quadrado. 
A classe 5, "Pesquisas Empíricas", foi formada por $22,3 \%$ das UCEs. As principais palavras que se relacionam a esta classe foram: ano, idade, entrevista, médiola, dado, faixa, estado, questionário, submeter, leitura, etário, coleta, temática, atitude, conteúdo e meio. O conteúdo da classe 5 trata principalmente de termos comumente utilizados na descrição de amostras em estudos empíricos quantitativos e qualitativos. Os trechos a seguir ilustram esse contexto: "O artigo se baseia nos dados de uma pesquisa em que foram entrevistadas seis mulheres entre 25 e 35 anos de idade, de nível socioeconômico médio, cujas respostas foram submetidas à análise de conteúdo" (Amazonas, Vieira, \& Pinto, 2011, p. 315); e "A coleta dos dados foi realizada por meio de contatos com homens e mulheres em universidades, locais de trabalho e em domicílio, na cidade do Recife, por meio de uma entrevista com duas perguntas e um questionário" (Almeida, Lima, Albuquerque, \& Antunes, 2005, p. 173).

O teste qui-quadrado foi significativo nessa classe para os artigos: Oliveira, $2008\left(\chi^{2}=14,14 ; p<0,001\right)$; Marcondes, Trierweiler, \& Cruz, $2006\left(\chi^{2}=6,5 ; p<0,05\right)$; Borges \& Seidl, $2012\left(\chi^{2}=6,5 ; p<0,05\right)$; Lermen \& Batista, $2018\left(\chi^{2}=4,18 ; p<0,05\right)$; e Vasquez, 2009 $\left(\chi^{2}=4,18 ; p<0,05\right)$. Apesar do número de artigos por ano ser pequeno - o que diminui o poder estatístico do teste qui-quadrado -, os anos de 2005, 2006, 2008 e 2009 aderiram a essa classe de forma marginalmente significativa (i.e., $p$ entre 0,05 e 0,1 ). Isso indica que o período anterior a 2010 foi marcado por publicações que, predominantemente, tratavam os temas gênero/ sexualidade de forma superficial ou transversal.

A classe 1, "Sexualidade e Desenvolvimento", foi responsável por $19,78 \%$ das UCEs. Os principais segmentos relacionados a esta classe foram: referir, maior, destacar, aspecto, problematizar, sexualidade, questão, forma, filho, maternidade, pai, lidar, papel, individual e expressão (Figura 2). O conteúdo desta classe representa os estudos que se voltaram para a discussão sobre sexualidade ou para os processos de desenvolvimento ligados predominantemente a exercícios de cuidado e parentalidade, principalmente das mulheres, no âmbito da família. Os trechos a seguir representam esse contexto: "O objetivo deste estudo consiste em apresentar alguns aspectos referentes ao diálogo sobre sexualidade entre pais e adolescentes, a partir do ponto de vista de mulheres que possuem filhos(as) adolescentes" (Savegnago \& Arpini, 2016, p. 130);
“[...] a partir do trabalho realizado, os professores conseguiram se instrumentalizar para lidar de forma mais potencializadora dos direitos humanos com as expressões de sexualidade na infância, bem como para atender os pais em suas dúvidas relacionadas ao tema" (Ciaffone \& Gesser, 2014, p. 775); "A menopausa representa transformações hormonais significativas que podem ser acompanhadas de mudanças sociais e emocionais. Além disso, a população idosa feminina tem apresentado maiores comprometimentos em relação à sexualidade do que os homens" (Crema, Tilio, \& Campos, 2017, p. 753); e "Acredita-se que este estudo possa contribuir de forma parcimoniosa para a promoção de mudanças de atitudes acerca da sexualidade da pessoa idosa, trazendo benefícios para a qualidade de vida dessa população" (Vieira, Coutinho, \& Saraiva, 2016, p. 196).

O teste qui-quadrado foi significativo nessa classe para agrupar os artigos: Garcia \& Gonçalves, 2019 $\left(\chi^{2}=6,32 ; p<0,05\right)$; Alcântara, Sousa, \& Silva, 2018 $\left(\chi^{2}=6,32 ; p<0,05\right)$; Savegnago \& Arpini, $2016\left(\chi^{2}=5,19\right.$; $p<0,05)$; Miranda, Timo, \& Belo, $2019\left(\chi^{2}=4,2 ; p<0,05\right)$; Prado, Fleith, \& Gonçalves, $2011\left(\chi^{2}=4,2 ; p<0,05\right)$. É importante também destacar que a palavra mulher foi a mais frequente na classe, junto com sexualidade $\left(\chi^{2}=8,29 ; p<0,01\right)$, e que a região Nordeste aderiu à classe de forma marginalmente significativa. Assim, o conteúdo dessa classe parece reunir estudos que tratavam de questões de gênero e sexualidade de mulheres, a educação sexual dos filhos, expressões de sexualidade em distintos contextos, como o domiciliar e o carcerário, desigualdade de oportunidades ou opressões sexistas relacionadas ao feminino.

A classe 4, "Violência contra a Mulher", foi responsável por 20,14\% das UCEs. Os principais elementos relacionados a esta classe foram: violência, mulher, subjetividade, rede, homem, considerar, importante, olhar, condição, vítima, auxiliar, ação, situação, sentido, estratégia e masculinidade (Figura 2). O conteúdo desta classe refere-se aos estudos sobre violência contra a mulher, destacadamente a importância de se compreender a subjetividade e o contexto para pensar em formas de atuação que visem combater o problema. Os trechos a seguir demonstram esse contexto: "Compreende-se que os resultados deste estudo reforçam as relações de gênero e a transgeracionalidade da violência como pontos importantes a serem considerados no momento de pensar e implementar pesquisas, ações e políticas referentes às mulheres em 
situação de violência” (Santos \& Moré, 2011, p. 221); "Considerando que a Psicologia Social auxilia para que práticas e ações sociais sejam problematizadas, este estudo tem como objetivo evidenciar como os sentidos de si e do Outro identificados em narrativas de homens autores de violência sustentam e justificam a ação violenta cometida" (Garcia \& Beiras, 2019, p. 45); e “. . promover discussões que propiciassem a reflexão das mulheres sobre novas formas de enfrentamento das situações de violência ou das consequências desta e formar uma rede social de apoio às mulheres e oportunizar vivências de interação entre as participantes para gerar aprendizagem, desenvolvendo mudanças na sua realidade social" (Ramos \& Oltramari, 2010, p. 419).

O teste qui-quadrado foi significativo nessa classe para agrupar os artigos: Bertagnoli \& Figueiredo, $2017\left(\chi^{2}=19,19 ; p<0,001\right)$; Souza \& Langaro, 2011 $\left(\chi^{2}=12,02 ; p<0,001\right)$; Leite, Dimenstein, Paiva, Carvalho, Amorim, \& França, $2016\left(\chi^{2}=9,19 ; p<0,01\right)$; Silva, $2010\left(\chi^{2}=7,99 ; p<0,01\right)$; Gonzaga \& Mayorga, $2019\left(\chi^{2}=7,59 ; p<0,01\right)$; Garcia \& Beiras, 2019 $\left(\chi^{2}=6,11 ; p<0,05\right)$; Molina, $2003\left(\chi^{2}=4,08 ; p<0,05\right)$; Santos \& Moré, $2011\left(\chi^{2}=4,08 ; p<0,05\right)$; e Dutra \& Mayorga, $2019\left(\chi^{2}=3,98 ; p<0,05\right)$. $\mathrm{O}$ ano de 2011 aderiu significativamente à classe $\left(\chi^{2}=9,63 ; p<0,01\right)$, e 2017 aderiu de forma não significativa.

A classe 2, "Estudos de Intervenção", foi responsável por $12,95 \%$ das UCEs. Os principais elementos que se relacionaram a esta classe foram: científico, projeto, comunitário, futuro, cartilha, base, visar, intervenção, atuar, experiência, desenvolver, realizar, relato, HIVlaids e curso (Figura 1). O conteúdo desta classe relaciona-se com os artigos que buscavam desenvolver ou discutir intervenções no campo da sexualidade e do gênero. Os trechos que expressam esse contexto são apresentados a seguir: "O texto é um relato de experiência em um projeto de extensão universitária que elaborou e testou junto a grupos comunitários uma cartilha sobre violência conjugal direcionada tanto a mulheres quanto a homens" (Lenz-de-Oliveira, Santos, Moura, Garcia, \& Gomes, 2010, p. 429); "O curso teve $15 \mathrm{~h}$ de duração, no decorrer de três semanas, com oficinas sobre sexualidade, DST/AIDS, drogas e planejamento de projetos. Foram realizadas atividades com base numa metodologia participativa e problematizadora" (Moskovics \& Calvetti, 2008, p. 211); e "Este artigo apresenta uma experiência de extensão universitária que objetivou promover um espaço socioeducativo com adolescentes do sexo feminino no universo dos direitos sexuais e sociais. O projeto foi desenvolvido por duas estudantes de Psicologia e dois de Serviço Social" (Cordeiro, Barbosa Filho, Santos, Oliveira, \& Araújo, 2010, p. 189).

$O$ teste qui-quadrado foi significativo nessa classe para integrar aos artigos: Lenz-de-Oliveira et al., $2010\left(\chi^{2}=26,95 ; p<0,001\right)$; Moskovics \& Calvetti, 2008 $\left(\chi^{2}=34,23 ; p<0,001\right)$; Santos \& Araujo, $2003\left(\chi^{2}=6,75\right.$; $p<0,01)$; Dias, 2001 ( $\left.\chi^{2}=7,76 ; p<0,01\right)$; Gesser \& Nuernberg, 2014 ( $\left.\chi^{2}=4,94 ; p<0,05\right)$; Ciaffone \& Gesser, $2014\left(\chi^{2}=4,94 ; p<0,05\right)$. O termo psicologia aparece como uma das palavras que se ligam à classe $\left(\chi^{2}=5,61\right.$; $p<0,05)$. Além disso, aderiram também os anos de $2001\left(\chi^{2}=7,76 ; p<0,01\right), 2008\left(\chi^{2}=9,17 ; p<0,01\right), 2010$ $\left(\chi^{2}=4,94 ; p<0,05\right)$ e $2014\left(\chi^{2}=9,3 ; p<0,01\right)$; e as regiões Nordeste $\left(\chi^{2}=5,84 ; p<0,05\right)$, de maneira significativa, $\mathrm{e}$ Sul, de forma marginalmente significativa.

A classe 3, "Perspectivas Críticas da Diversidade", foi responsável por $24,82 \%$ das UCEs. Os principais elementos relacionados a esta classe foram: método, sexual, diversidade, produção, concepção, discursivo, escolar, educação, CFP (Conselho Federal de Psicologia), LGBTs/homossexualidade, acadêmico, teórico, indivíduo, investigar, analisar e discurso (Figura 1). O conteúdo desta classe retrata estudos de diversidade sexual e de gênero, principalmente aqueles cujo método foi a análise do discurso; aparecem ainda temáticas de educação sobre diversidade e a atuação do CFP. Os trechos a seguir ilustram esse contexto: "Assim, o objetivo dessa pesquisa foi analisar as concepções de alunos de graduação em Psicologia interessados nas temáticas de gênero e sexualidade, com relação à diversidade sexual e de gênero, assim como seus conhecimentos sobre as declarações do CFP a respeito das homossexualidades e identidades trans" (Mizael, Gomes, \& Marola, 2019, p. 1); "Entrevistamos três diretores e quatro coordenadores pedagógicos do ensino fundamental II, buscando incitar as produções discursivas presentes no contexto educacional acerca da concepção da educação sexual" (Melo, Arruda, Alencar, \& Colaço, 2010, p. 347); e "Examinar as crenças de psicólogos/as sobre indivíduos e grupos atingidos pelo preconceito contribui para a preparação do/a profissional no atendimento a esse público. Neste estudo, investigou-se a relação entre preconceito e crenças sobre diversidade sexual e de gênero em psicólogos/as brasileiros/as" (Gaspodini \& Falcke, 2018, p. 744). 
$\mathrm{O}$ teste qui-quadrado foi significativo nessa classe para os artigos: Melo et al., $2010\left(\chi^{2}=18,57\right.$; $p<0,001)$; Borges, Canuto, Oliveira, \& Vaz, 2013 $\left(\chi^{2}=18,57 ; p<0,001\right)$; Mizael et al., $2019\left(\chi^{2}=18,57\right.$; $p<0,001)$; Ciribelli \& Rasera, $2019\left(\chi^{2}=11,25\right.$; $p<0,001)$; Gaspodini \& Falcke, $2018\left(\chi^{2}=8,36\right.$; $p<0,01$ ); Rios et al., 2017 ( $\chi^{2}=8,31 ; p<0,01$ ); e Melo \& Barreto, $2014\left(\chi^{2}=6,31 ; p<0,05\right)$. É importante destacar que a palavra gênero é a mais frequente da classe e aderiu significativamente $\left(\chi^{2}=9,1 ; p<0,01\right)$, bem como psicologia ( $\left.\chi^{2}=4,15 ; p<0,05\right)$. Além disso, o ano de 2013 se ligou significativamente à classe $\left(\chi^{2}=18,57 ; p<0,001\right)$, e o de 2019 aderiu de forma não significativa; e a região Centro-Oeste aderiu significativamente $\left(\chi^{2}=11,14 ; p<0,001\right)$

O conteúdo das classes no dendograma obtido pela análise do corpus (Figura 2) indica que as classes 1 e 4 reúnem estudos sobre as opressões sexistas contra mulheres, tanto em relação a sua sexualidade e processos de desenvolvimento pessoal ou profissional como quanto à violência contra a mulher e o encarceramento. Por outro lado, as classes 2 e 3 reúnem artigos que trazem perspectivas críticas da diversidade sexual e do gênero, muitos deles focados em intervenções educativas; ambas as classes se ligam às palavras gênero e psicologia, o que indica que essas pesquisas se voltam para uma abordagem mais geral de diversidade sexual e de gênero, muitas vezes com enfoque em saúde. Já a classe 5 desponta como um agrupamento à parte, em que se reúnem estudos que fazem "comparações de gênero" e buscam diferenças entre homens e mulheres para alguma variável de desfecho; ou trazem a sexualidade/gênero como um de vários prismas analíticos ou tópicos de discussão.

Em seguida, a análise de similitude, apresentada na Figura 3, permitiu observar a interconexão e o nível de relação entre as comunidades formadas pelas palavras, com base no índice de co-ocorrências, e entre as palavras isoladamente, pela frequência.

Inicialmente, quanto às comunidades formadas, pode-se ver uma comunidade em que gênero é central e se liga a verbos como partir, investigar, analisar, produzir e compreender, bem como a identidade. Se liga ainda à palavra estudo, que a conecta com o termo análise, que está contido na comunidade gênero, mas forma uma comunidade própria e traz consigo dado, conteúdo e utilizar. Na comunidade em que sexualidade é central, ela se liga com produção, construção, adolescente e idoso. Tais resultados indicam a existência de um conjunto de estudos que buscam analisar ou compreender gênero e identidade, principalmente a partir de análises de conteúdo. E esses estudos costumam discutir temas como a sexualidade em distintas etapas geracionais ou do desenvolvimento humano.

No centro da imagem, a comunidade relação contém também os termos familiar, apontar, mudança, HIV e sistema, e se se conecta a sexual, diversidade, direito, escola e preconceito. A palavra saúde está contida nessa comunidade, mas também forma sua própria, trazendo consigo sentido, problema, ação, serviço, público e família. Assim, parece existir diferentes estudos que investigam processos relacionais, como estratégias de mudança em relação ao preconceito contra a diversidade sexual e pessoas vivendo com HIV/aids; tais ações de intervenção acontecem em âmbito familiar e em escolas. Além disso, esses estudos costumam abordar temas ligado à saúde, como os problemas na qualidade e no acesso ao serviço público de saúde e as Estratégias de Saúde na Família.

Na parte inferior da Figura 3, há uma comunidade em que mulher é central e se liga a desenvolvimento, discurso, problematizar, violência, feminino e papel. A palavra homem aparece dentro dessa comunidade e forma sua própria comunidade, trazendo consigo evidenciar, cuidado e campo. Igualmente, social está contido na comunidade mulher e forma sua própria comunidade, trazendo consigo psicologia, perspectiva e prático. Isso indica a existência de um conjunto de estudos que problematizam os estereótipos acerca da mulher e do feminino, principalmente por meio da análise do discurso. Debatem, por exemplo, processos de desigualdade de oportunidades e desenvolvimento, opressões sexistas, violência doméstica perpetrada por homens e encarceramento feminino. $\mathrm{O}$ aspecto social do problema é um ponto de destaque, e a Psicologia/psicóloga aparece nesse eixo como um saber/profissional da saúde cujas práticas de cuidado devem se voltar para esses problemas. Na parte de baixo, a comunidade trabalho contém presente, discutir, visar, realizar, pesquisa, entrevista, experiência e qualitativo. Esses termos situam a natureza metodológica dos estudos que se voltam para questões de sexismo, gênero e o feminino. 


\section{Figura 3.}

Análise de similitude.

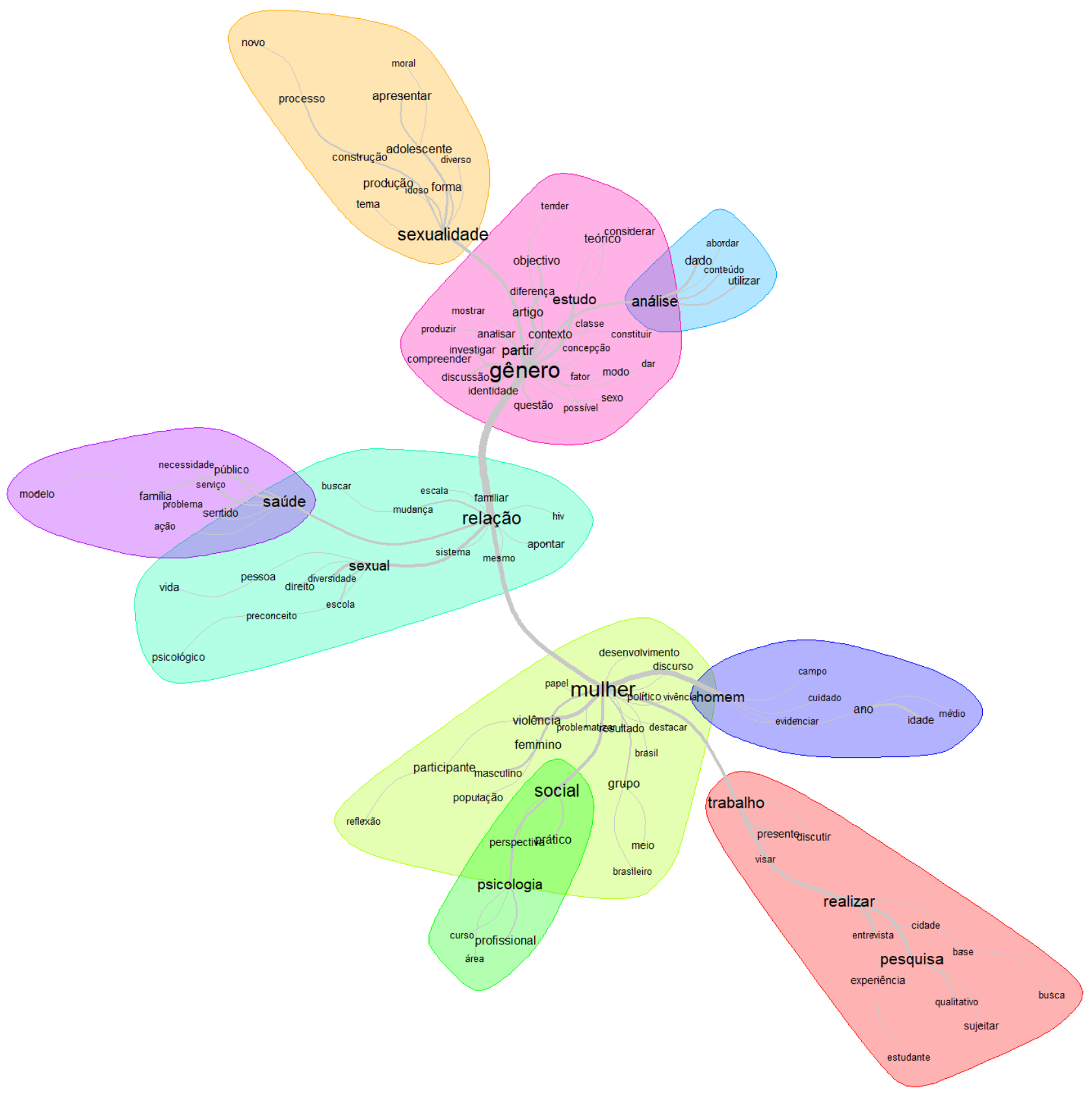

É possível ainda verificar a formação de dois grupos de comunidades. Na parte superior da figura, o termo gênero aparece como central, conectado a sexualidade, análise e ao eixo relação sexual e saúde. Na parte inferior da figura, a palavra mulher é central e aparece muito próxima e conectada ao termo social. Esse segundo grupo de comunidades também se liga de forma mais fraca à comunidade cuja palavra central é homem, e seus termos principais são trabalho, realizar e pesquisa. Além disso, apesar de mais afastado e com uma ligação mais fraca, liga-se ao eixo relação sexual e saúde, por meio do qual se conecta com gênero. Assim, percebe-se a formação de dois eixos principais dos estudos: um voltado a discussões sobre gênero e diversidade sexual, passando por questões de desenvolvimento, e outro relacionado com uma perspectiva de disparidades de gênero e sexismo. Apesar de uma maior proximidade da comunidade gênero com a relação, ambos os eixos temáticos se conectam pelo foco nas relações, 
sejam familiares ou com outras redes de apoio; e pelo foco em intervenções em educação e saúde para enfrentar os problemas na área, como o preconceito.

Apesar do avanço dos estudos de gênero, da disseminação do termo e da incorporação ampla do conceito, em muitos dos trabalhos analisados ainda é comum a referência exclusiva a mulheres, em especial nos estudos sobre violência - marcando uma porosidade conceitual ainda presente, como se estudos de gênero fossem análogos aos estudos sobre mulheres, e a violência contra elas ocuparia espaço de centralidade. Apesar do crescimento das pesquisas sobre masculinidades e da dilação do campo de estudos de gênero, estes quase não aparecem na PCP, o que leva a supor que talvez estejam sendo mais divulgadas em periódicos temáticos, como os citados no início do texto - Revista Estudos Feministas, Cadernos Pagu e Sexualidad, Salud y Sociedad -, nos quais é possível encontrar inclusive dossiês sobre o tema. Ao mesmo tempo, o termo gênero, ligado a outros como produzir, analisar e estudo, sugere uma incorporação cada vez maior do gênero como lente de análise. A força do termo relação talvez também evidencie a dimensão relacional das discussões sobre gênero e a capilaridade dos estudos em diversas áreas ou como ainda não ocupa a centralidade da discussão em algumas produções.

Parece importante destacar a ausência da discussão sobre raça em uma perspectiva interseccional, já que outros marcadores interseccionais, como geração e classe, mesmo que de forma sutil, figuram em muitas das produções analisadas. Embora apareçam as palavras diversidade e classe, não se constata uma discussão que perpassa os marcadores sociais de forma mais integrada. Martins, Santos e Colosso (2013), ao analisarem as publicações da psicologia sobre raça e a revista Psicologia: Ciência e Profissão, encontraram o dobro de artigos sobre a temática. Em uma distribuição bastante equânime dos 41 artigos entre 14 periódicos, a PCP aparece com 8, destacando-se. No entanto, o que ressaltamos aqui é a ausência de uma perspectiva interseccional, visto que a temática não aparece associada, por exemplo, a gênero e sexualidade, foco deste artigo.

Em suma, o panorama da revista indica uma produção em sintonia com o panorama da produção nacional e internacional da área, também implicada e influenciada pelas mudanças no panorama sócio-político nacional. Entretanto, considerando a centralidade da revista Psicologia: Ciência $e$ Profissão para a profissão e para a área como um todo, depreende-se que a produção ainda é aquém da dimensão que as temáticas de gênero e sexualidade ocupam no cenário atual.

\section{Considerações finais}

Os estudos de gênero/sexualidade publicados pela revista Psicologia: Ciência e Profissão se organizaram em duas comunidades temáticas, uma voltada a discussões sobre gênero e diversidade sexual e outra a sexismo e disparidades de gênero. Ambas foram marcadas pelas determinações jurídico-legais ocorridas no Brasil nas últimas duas décadas. Alguns importantes marcos relacionados a sexualidade e gênero no período incluem: em 2004, a implementação da política de combate ao preconceito contra orientação sexual e identidade de gênero (Brasil sem Homofobia); em 2006, a Lei Maria da Penha busca coibir a violência doméstica e familiar contra a mulher; em 2011, o STF reconhece o casamento entre pessoas do mesmo sexo. Tais fatos certamente marcaram os interesses dos/as pesquisadores/as. Assim, além dos posicionamentos do CFP por meio de Resoluções, comunicados ou diretrizes, as publicações da revista Psicologia: Ciência e Profissão têm trazido ao debate público e científico dados, análises, discussões e intervenções na área de sexualidade e gênero.

Os resultados do presente estudo, que buscou analisar essas produções, indicam que os marcos jurídico-legais afetaram o campo de saberes e fazeres da Psicologia, que, por sua vez, tensionam na sociedade brasileira aspectos importantes para o debate público em torno de sexualidade/gênero. Exemplo disso são as temáticas de diversidade sexual e de gênero e de violência contra a mulher, cuja frequência de publicações aumentou em momentos de intensificação do debate social e das mudanças de legislação no tema - mesmo que muitas vezes por um viés familista. Além disso, ainda que em termos numéricos a produção não tenha a expressão que as temáticas ocupem no debate social, a revista Psicologia: Ciência e Profissão tem papel estratégico não apenas na divulgação da produção das áreas de gênero e sexualidade - em amplitude e diversidade-, mas também no fomento desses debates, aceitando-os em seu escopo, e especialmente na promoção de números especiais que contemplam a temática e suas interfaces. 


\section{Referências}

Alcântara, R. L. S., Sousa, C. P. C., \& Silva, T. S. M. (2018). Infopen Mulheres de 2014 e 2018: Desafios para a Pesquisa em Psicologia. Psicologia: Ciência e Profissão, 38(esp2), 88-101.

Almeida, N. D. V., Lima, A. K. B., Albuquerque, C. M., \& Antunes, L. (2005). As relações de gênero e as percepções dos/das motoristas no âmbito do sistema de trânsito. Psicologia: Ciência e Profissão, 25(2), 172-185.

Amazonas, M. C. L. A., Vieira, L. L. F., \& Pinto, V. C. (2011). Modos de subjetivação femininos, família e trabalho. Psicologia: Ciência e Profissão, 31(2), 314-327.

Araújo, M. F. (2002). Amor, casamento e sexualidade: velhas e novas configurações. Psicologia: Ciência e Profissão, 22(2), 70-77.

Azerêdo, S. (2010). Encrenca de gênero nas teorizações em psicologia. Revista Estudos Feministas, 18(1), 175-188.

Banuth, R. F. \& Santos, M. A. (2016). Vivências de discriminação e resistência de uma prostituta negra. Psicologia: Ciência e Profissão, 36(3), 763-776.

Bertagnoli, M. S. F. F. \& Figueiredo, M. A. C. (2017). Gestantes soropositivas ao HIV: maternidade, relações conjugais e ações da Psicologia. Psicologia: Ciência e Profissão, 37(4), 981-994.

Borges, L. S., Canuto, A. A. A., Oliveira, D. P., \& Vaz, R. P. (2013). Abordagens de gênero e sexualidade na Psicologia: revendo conceitos, repensando práticas. Psicologia: Ciência e Profissão, 33(3), 730-745.

Borges, L. M. \& Seidl, E. M. F. (2012). Percepções e comportamentos de cuidados com a saúde entre homens idosos. Psicologia: Ciência e Profissão, 32(1), 66-81.

Camargo, B. V. \& Justo, A. M. (2013). Iramuteq: um software gratuito para análise de dados textuais. Temas em Psicologia, 21(2), 513-518.

Cedaro, J. J., Boas, L. M. S. V., \& Martins, R. M. (2012). Adolescência e sexualidade: um estudo exploratório em uma escola de Porto Velho-RO. Psicologia: Ciência e Profissão, 32(2), 320-339.

Ciaffone, A. C. R. \& Gesser, M. (2014). Integração saúde e educação: contribuições da psicologia para a formação de educadores de uma creche em sexualidade infantil. Psicologia: Ciência e Profissão, 34(3), 774-787.

Ciribelli, C. J. M. \& Rasera, E. F. (2019). Construções de sentido sobre a diversidade sexual: outro olhar para a educação infantil. Psicologia: Ciência e Profissão, 39, e175599, 1-15.

Corrêa, S. \& Petchesky, R. (1996). Direitos sexuais e reprodutivos: uma perspectiva feminista. Physis: Revista de Saúde Coletiva, 6(1-2), 147-177.

Cordeiro, R. L. M., Barbosa Filho, E. A., Santos, G. M. N. C., Oliveira, L. A., \& Araújo, R. B. (2010). Meninas de moral: experiências socioeducativas em um bairro popular do Recife. Psicologia: Ciência e Profissão, 30(1), 188-199.

Crema, I. L., Tilio, R., \& Campos, M. T. A. (2017). Repercussões da menopausa para a sexualidade de idosas: revisão integrativa da literatura. Psicologia: Ciência e Profissão, 37(3), 753-769.

D’Angelo, L. B., Lima, V. P., Costa, V. A., Hernández, J. G., Rocha, B. S., Pinho, G. S. A., \& Uziel, A. P. (2018). Performatividades de gênero em unidades prisionais femininas do Rio de Janeiro. Psicologia: Ciência e Profissão, 38(esp2), 44-59.

Decreto $n^{\circ}$ 79.822, de 17 de junho de 1977. (1977) Regulamenta a Lei no 5.766, de 20 de dezembro de 1971, que criou o Conselho Federal e os Conselhos Regionais de Psicologia e dá outras providências. Brasília, DF: Presidência da República.

Dessen, M. A. (2010). Estudando a família em desenvolvimento: desafios conceituais e teóricos. Psicologia: Ciência e Profissão, 30(n.spe), 202-219.

Dias, C. A. (2001). Considerações sobre elaboração de currículos para formação de psicólogos: a partir de uma perspectiva didática. Psicologia: Ciência e Profissão, 21(3), 36-49.

Dutra, J. C. O., \& Mayorga, C. (2019). Mulheres indígenas em movimentos: possíveis articulações entre gênero e política. Psicologia: Ciência e Profissão, 39(n.spe), 113-129.

Garcia, A. L. C. \& Beiras, A. (2019). A psicologia social no estudo de justificativas e narrativas de homens autores de violência. Psicologia: Ciência e Profissão, 39(n.esp2), e225647, 45-58. 
Garcia, A. M. \& Gonçalves, H. S. (2019). Sexualidade na medida socioeducativa de internação: traçando pistas por uma revisão da literatura. Psicologia: Ciência e Profissão, 39, e184463, 1-16.

Gaspodini, I. B. \& Falcke, D. (2018). Relações entre preconceito e crenças sobre diversidade sexual e de gênero em psicólogos/as brasileiros/as. Psicologia: Ciência e Profissão, 38(4), 744-757.

Germano,I.M.P., Monteiro, R.Á.F.G., \&Liberato,M.T.C. (2018). Criminologiacrítica,feminismoeinterseccionalidade na abordagem do aumento do encarceramento feminino. Psicologia: Ciência e Profissão, 38(n.esp2), 27-43.

Gesser, M., \& Nuernberg, A. H. (2014). Psicologia, sexualidade e deficiência: novas perspectivas em direitos humanos. Psicologia: Ciência e Profissão, 34(4), 850-863.

Gonzaga, P. R. B. \& Mayorga, C. (2019). Violências e instituição maternidade: uma reflexão feminista decolonial. Psicologia: Ciência e Profissão, 39(n.esp2), e225712, 59-73.

Guedes, M. A. (2006). Intervenções psicossociais no sistema carcerário feminino. Psicologia: Ciência e Profissão, 26(4), 558-569.

Guedes, M. E. F. (1995). Gênero, o que é isso?. Psicologia: Ciência e Profissão, 15(1-3), 4-11.

Jablonski, B. (2010). A divisão de tarefas domésticas entre homens e mulheres no cotidiano do casamento. Psicologia: Ciência e profissão, 30(2), 262-275.

Junqueira, R. D. (2018). A invenção da "ideologia de gênero": a emergência de um cenário político-discursivo e a elaboração de uma retórica reacionária antigênero. Revista Psicologia Política, 18(43), 449-502.

Lago, M. C. S.; Uziel, A. P. (2014) Intersecções: psicologia e estudos de gênero na revista Estudos Feministas (2003-2014). Labrys, 26, 1-10.

\section{Psicologia: Ciência e Profissão38}

Lei $n^{o} 11.340$, de 7 de agosto de 2006. (2006). Cria mecanismos para coibir a violência doméstica e familiar contra a mulher, nos termos do $\$ 8^{\circ}$ do art. 226 da Constituição Federal, da Convenção sobre a Eliminação de Todas as Formas de Discriminação contra as Mulheres e da Convenção Interamericana para Prevenir, Punir e Erradicar a Violência contra a Mulher; dispõe sobre a criação dos Juizados de Violência Doméstica e Familiar contra a Mulher; altera o Código de Processo Penal, o Código Penal e a Lei de Execução Penal; e dá outras providências. Brasília, DF: Presidência da República.

Leite, J. F., Dimenstein, M., Paiva, R., Carvalho, L., Amorim, A. K. M. A., \& França, A. (2016). Sentidos da saúde numa perspectiva de gênero: um estudo com homens da cidade de Natal/RN. Psicologia: Ciência e Profissão, 36(2), 341.

Lermen, H. S. \& Batista, M. B. B. (2018). Masculinidades no cárcere: homens que visitam suas parceiras privadas de liberdade. Psicologia: Ciência e Profissão, 38(n.esp2), 73-87.

Lenz-de-Oliveira, K., Santos, M. M., Moura, S. A., Garcia, W. I., \& Gomes, R. (2010). Elaborando uma cartilha sobre as ambiguidades da violência conjugal. Psicologia: Ciência e Profissão, 30(2), 428-439.

Lima, A. M. S., Barros, E. S., Varjão, R. L., Nogueira, M. S., Santos, V. F., Deda, A. V., Varjão, L. L., Jesus, L. K. A., Mendonça, A. K. R. H., Santana, V. R., \& Lima, S. O. (2019). Prevalência da depressão nos acadêmicos da área de saúde. Psicologia: Ciência e Profissão, 39, e187530, 1-14.

Macedo, E. O. S., \& Conceição, M. I. G. (2015). Significações sobre adolescência e saúde entre participantes de um grupo educativo de adolescentes. Psicologia: Ciência e Profissão, 35(4), 1059-1073.

Marcondes, M. V., Trierweiler, M., \& Cruz, R. M. (2006). Sentimentos predominantes após o término de um relacionamento amoroso. Psicologia: Ciência e Profissão, 26(1), 94-105.

Martins, E., Santos, A. O., \& Colosso, M. (2013). Relações étnico-raciais e psicologia: publicações em periódicos da SciELO e Lilacs. Psicologia: Teoria e Prática, 15(3), 118-133.

Melo, E. M. O., Arruda, D. P., Alencar, H. F., \& Colaço, V. F. R. (2010). O dito e o não dito na educação sexual: uma produção discursiva. Psicologia: Ciência e Profissão, 30(2), 346-361.

Melo, R. A., \& Barreto, D. J. (2014). Formação em Psicologia: discursos e saberes sobre experimentações de gênero. Psicologia: Ciência e Profissão, 34(3), 676-689.

Meurer, B., \& Strey, M. N. (2012). Problematizando as práticas psicológicas no modo de compreender o fenômeno assédio moral. Psicologia: Ciência e Profissão, 32(2), 452-471. 
Miranda, J. J., Timo, A. L. R., \& Belo, F. R. R. (2019). Crítica à Teoria da Maternidade em Winnicott: é preciso ser mulher para cuidar de crianças?. Psicologia: Ciência e Profissão, 39, e176863, 1-14.

Mizael, T. M., Gomes, A. R., \& Marola, P. P. (2019). Conhecimentos de estudantes de Psicologia sobre normas de atuação com indivíduos LGBTs. Psicologia: Ciência e Profissão, 39, e182761, 1-20.

Molina, A. M. R. (2003). Prostituição juvenil: uma condição existencial em busca de seus sentidos. Psicologia: Ciência e Profissão, 23(2), 22-29.

Moskovics, J. M. \& Calvetti, P. Ü. (2008). Formação de multiplicadores para a prevenção das DST/aids numa universidade espanhola. Psicologia: Ciência e Profissão, 28(1), 210-217.

Nunes, M. F. O. \& Noronha, A. P. P. (2009). Autoeficácia para atividades ocupacionais e interesses profissionais em estudantes do ensino médio. Psicologia: Ciência e Profissão, 29(1), 102-115.

Oliveira, É. C. S. (2014). “Eu também sei atirar”!: reflexões sobre a violência contra as mulheres e metodologias estético-políticas. Psicologia: Ciência e Profissão, 34(3), 555-573.

Oliveira, K. L. (2008). Compreensão da leitura, atitudes de leitura e desesperança em universitários. Psicologia: Ciência e Profissão, 28(4), 820-831.

Oliveira, J. W., Rosato, C. M., Nascimento, A. M. R., \& Granja, E. (2018). "Sabe a minha identidade? Nada a ver com genital”: vivências travestis no cárcere. Psicologia: Ciência e Profissão, 38(n.esp2), 159-174.

Pantoja, F. C., Bucher, J. S. N. F., \& Queiroz, C. H. (2007). Adolescentes grávidas: vivências de uma nova realidade. Psicologia: Ciência e Profissão, 27(3), 510-521.

Parker, R. G. (1995). A construção social e cultural do risco sexual, ou como fazer pesquisa (em sexualidade) em uma epidemia. Physis: Revista de Saúde Coletiva, 5(1), 85-98.

Parker, R., Quemmel, R., Guimares, K., Mota, M., \& Terto Jr, V. (1995). AIDS prevention and gay community mobilization in Brazil. Development Journal of the Society for International Development English Edition, 2, 49-53.

Prado, R. M., Fleith, D. S., \& Gonçalves, F. C. (2011). O desenvolvimento do talento em uma perspectiva feminina. Psicologia: Ciência e Profissão, 31(1), 134-145.

Ramos, M. E., \& Oltramari, L. C. (2010). Atividade reflexiva com mulheres que sofreram violência doméstica. Psicologia: Ciência e Profissão, 30(2), 418-427.

Rios, R. R. (2006). Para um direito democrático da sexualidade. Horizontes Antropológicos, 12(26), 71-100.

Rios, R. R., Resadori, A. H., Silva, R., \& Vidor, D. M. (2017). Laicidade e Conselho Federal de Psicologia: dinâmica institucional e profissional em perspectiva jurídica. Psicologia: Ciência e Profissão, 37(1), 159-175.

Sá, A. A. M. \& Santos, C. V. M. (2018). A vivência da sexualidade de pessoas que vivem com HIV/aids. Psicologia: Ciência e Profissão, 38(4), 773-786.

Sacco, A. M., Valiente, L., Vilanova, F., Wendt, G. W., DeSousa, D. A., \& Koller, S. H. (2016). Perfil dos bolsistas de produtividade em pesquisa do CNPq atuantes em Psicologia no triênio 2012-2014. Psicologia: Ciência e Profissão, 36(2), 292-303.

Salvaro, G. I. J., Estevam, D. O., \& Felipe, D. F. (2014). Mulheres em cooperativas rurais virtuais: reflexões sobre gênero e subjetividade. Psicologia: Ciência e Profissão, 34(2), 390-405.

Sampaio, I. T. A. \& Vieira, M. L. (2009). Autodescrição de adolescentes segundo o gênero e a ordem de nascimento. Psicologia: Ciência e Profissão, 29(3), 574-587.

Santos, A. C. W. \& Moré, C. L. O. O. (2011). Impacto da violência no sistema familiar de mulheres vítimas de agressão. Psicologia: Ciência e Profissão, 31(2), 220-235.

Santos, A. P., Barbato, S. B., \& Delmondez, P. (2018). Polifonia na produção do binarismo de gênero em brincadeiras na primeira infância. Psicologia: Ciência e Profissão, 38(4), 758-772.

Santos, C. V. M., \& Gomes, I. C. (2016). The LWord: discussões em torno da parentalidade lésbica. Psicologia: Ciência e Profissão, 36(1), 101-115.

Santos, M. M. R., \& Araujo, T. C. C. F. (2003). A clínica da intersexualidade e seus desafios para os profissionais de saúde. Psicologia: Ciência e Profissão, 23(3), 26-33. 
Savegnago, S. D. O., \& Arpini, D. M. (2016). A abordagem do tema sexualidade no contexto familiar: o ponto de vista de mães de adolescentes. Psicologia: Ciência e Profissão, 36(1), 130-144.

Silva, S. G. (2000). Masculinidade na história: a construção cultural da diferença entre os sexos. Psicologia: Ciência e Profissão, 20(3), 8-15.

Silva, S. G. (2006). A crise da masculinidade: uma crítica à identidade de gênero e à literatura masculinista. Psicologia: Ciência e Profissão, 26(1), 118-131.

Silva, S. G. (2010). Preconceito e discriminação: as bases da violência contra a mulher. Psicologia: Ciência e Profissão, 30(3), 556-571.

Siqueira, M. J. T. \& Ferreira, E. S. (2003). Saúde das professoras das séries iniciais: o que o gênero tem a ver com isso?. Psicologia: Ciência e Profissão, 23(3), 76-83.

Sousa, A. C. G. \& Brandão, S. N. (2008). Como é ser adolescente do sexo feminino na periferia?. Psicologia: Ciência e Profissão, 28(1), 82-97.

Souza, M. \& Langaro, F. (2011). Desconstruir para problematizar matrizes identitárias. Psicologia: Ciência e Profissão, 31(3), 568-581.

Teixeira, F. S., Marretto, C. A. R., Mendes, A. B., \& Santos, E. N. (2012). Homofobia e sexualidade em adolescentes: trajetórias sexuais, riscos e vulnerabilidades. Psicologia: Ciência e Profissão, 32(1), 16-33.

Terto Junior, V. (1989). No escurinho do cinema: socialidade orgástica nas tardes cariocas (dissertação de mestrado em Psicologia). Pontifícia Universidade Católica do Rio de Janeiro, Rio de Janeiro, RJ, Brasil.

Terto Junior, V. (1997). Reinventando a vida: histórias sobre a homossexualidade e aids no Brasil (tese de doutorado em Psicologia). Pontifícia Universidade Católica do Rio de Janeiro, Rio de Janeiro, RJ, Brasil.

Tokuda, A. M. P., Peres, W. S., \& Andrêo, C. (2016). Família, gênero e emancipação psicossocial. Psicologia: Ciência e Profissão, 36(4), 921-931.

Vasquez, G. C. F. (2009). A Psicologia na área rural: os assentamentos da reforma agrária e as mulheres assentadas. Psicologia: Ciência e Profissão, 29(4), 856-867.

Veras,J.F.(2007).Adoecimentopsíquicoemmulheresportadoras dovírusHIV:umdesafioparaaclínicacontemporânea. Psicologia: Ciência e Profissão, 27(2), 266-275.

Vieira, K. F. L., Coutinho, M. P. L., \& Saraiva, E. R. A. (2016). A sexualidade na velhice: representações sociais de idosos frequentadores de um grupo de convivência. Psicologia: Ciência e Profissão, 36(1), 196-209.

Vieira, K. F. L., Nóbrega, R. P. M., Arruda, M.V.S., \&Veiga, P. M. Melo. (2016). Representação social das relações sexuais: um estudo transgeracional entre mulheres. Psicologia: Ciência e Profissão, 36(2), 329-340.

Zambenedetti, G., Piccinini, C. A., Sales, A. L. L. F., Paulon, S. M., \& Silva, R. A. N. (2014). Psicologia e análise institucional: contribuições para os processos formativos dos agentes comunitários de saúde. Psicologia: Ciência e Profissão, 34(3), 690-703.

\section{Adolfo Pizzinato}

Doutor em Psicologia pela Univesitat Autònoma de Barcelona e Professor do Instituto de Psicologia da Universidade Federal do Rio Grande do Sul, no Programa de Pós-Graduação em Psicologia, Porto Alegre - RS. Brasil.

E-mail: adolfopizzinato@hotmail.com

(D) http://orcid.org/0000-0002-1777-5860

Damião Soares de Almeida-Segundo

Mestre em Psicologia pela Universidade Federal do Ceará. Doutorando em Psicologia pela Universidade Federal do Rio Grande do Sul, Porto Alegre - RS. Brasil.

E-mail: damiao_soares@hotmail.com

(D) http://orcid.org/0000-0003-2407-0583

\section{Anna Paula Uziel}

Doutora em Ciências Sociais pela Universidade Estadual de Campinas (Unicamp) e Professora do Instituto de Psicologia da Universidade do Estado do Rio de Janeiro, no Programa de Pós-Graduação em Psicologia Social, Rio de Janeiro - RJ. Brasil.

E-mail: uzielap@gmail.com

(i) http://orcid.org/0000-0001-7807-3910 
Endereço para envio de correspondência:

Universidade Federal do Rio Grande do Sul - Instituto de Psicologia. Rua Ramiro Barcelos, 2600, sala 204, Santa Cecília. CEP: 90035-003. Porto Alegre - RS. Brasil

Recebido 08/05/2020

Aceito 16/06/2020

Received 05/08/2020

Approved 06/16/2020

Recibido 08/05/2020

Aceptado 16/06/2020

Como citar: Pizzinato, A., Almeida-Segundo, D. S., \& Uziel, A. P. (2020). Gênero e Sexualidade: Análise das Publicações na Revista Psicologia: Ciência e Profissão (1995-2019). Psicologia: Ciência e Profissão, 40, 1-17. https://doi.org/10.1590/1982-3703003237767

How to cite: Pizzinato, A., Almeida-Segundo, D. S., \& Uziel, A. P. (2020). Gender and Sexuality: Analysis of Publications in the Journal Psicologia: Ciência e Profissão (1995-2019). Psicologia: Ciência e Profissão, 40, 1-17. https://doi.org/10.1590/1982-3703003237767

Cómo citar: Pizzinato, A., Almeida-Segundo, D. S., \& Uziel, A. P. (2020). Género y Sexualidad: Análisis de Publicaciones en la Revista Psicologia: Ciência e Profissão (1995-2019). Psicologia: Ciência e Profissão, 40, 1-17. https://doi.org/10.1590/1982-3703003237767 